SEGURADO, Rosemary. A agenda da multidão e o webativismo na cidade de São Paulo. História, Ciências, SaúdeManguinhos, Rio de Janeiro, v.22, supl., dez. 2015, p.1673-1691.

\title{
Resumo
}

\section{A agenda da multidão e o webativismo na cidade de São Paulo}

\section{The crowdsourcing and cyberactivism agenda in São Paulo city}

\section{Rosemary Segurado}

Professora, Programa de Estudos Pós-graduados em Ciências Sociais/ Pontifícia Universidade Católica de São Paulo (PUC-SP); pesquisadora, Núcleo de Estudos em Arte, Mídia e Política/PUC-SP. Rua Monte Alegre, 984

05014-901 - São Paulo - SP - Brasil roseseg@uol.com.br

Recebido para publicação em julho de 2014. Aprovado para publicação em outubro de 2015.
Aborda os resultados da pesquisa que analisou 144 perfis do Facebook para verificar o uso das mídias digitais na definição da agenda de ações que estabelecem, na cidade de São Paulo, organização, mobilização e debate sobre temas sociais, políticos e culturais, tais como questões étnicas, raciais, de gênero, de direito à cidade, entre outras. A escolha dessa plataforma foi realizada com base no crescimento de sua apropriação para as ações políticas. $O$ estudo detectou que a incorporação de ferramentas digitais na ação política vem proporcionando um conjunto de mudanças nos processos de discussão de temas sociais, políticos e culturais, além de redimensionar as instâncias de formulação e de deliberação, possibilitando a inovação nas formas de participação dos atores.

Palavras-chave: cibercultura; ciberpolítica; redes digitais; práticas políticas; multidão.

\section{Abstract}

This article presents the results of a study that analyzed 144 Facebook profiles to identify how digital media are used in setting the agendas for discussions and in organizing and mobilizing people about social, political and cultural topics like ethnic, racial, gender, and citizens' rights issues in São Paulo city. This platform was chosen because of its growing appropriation for political actions. The study found that the incorporation of digital tools in political action is bringing about a number of changes in the discussion of social, political, and cultural topics, and redefining the ways that agendas and deliberations are organized, fostering innovative forms of participation by social actors.

Keywords: cyberculture; cyberpolitics; digital networks; political practices; crowd. 
$\mathrm{O}$ presente artigo traz os resultados da pesquisa "Webativismo na cidade de São Paulo: caracterização e análise dos temas que orientaram as ações dos coletivos de cibercultura e ciberpolítica no município de São Paulo entre 2011 e 2012". O estudo analisou 144 perfis do Facebook para verificar o uso das mídias digitais na definição da agenda de ações que definem a organização, a mobilização e o debate sobre questões sociais, políticas e culturais. Em 2012, o Facebook atingiu um bilhão de usuários, e o Brasil estava entre os cinco países com maior número de membros na rede social, que é a mais utilizada pelos brasileiros (Facebook atinge..., 2012; Brasil é o segundo..., 2012).

O primeiro passo foi identificar os coletivos a partir das ações culturais e políticas. Posteriormente, iniciamos a identificação dos temas e dos debates diretamente relacionados a essas ações. A análise desses temas mostrou sua especificidade e a perspectiva norteadora das práticas adotadas pelos grupos.

A organização dos coletivos por eixos temáticos permitiu analisar o desenvolvimento de ações conjuntas, prática frequente entre os coletivos pesquisados. Mesmo que as ações cotidianas fossem orientadas por perspectivas diferentes, em momentos pontuais poderiam se unir em uma ação comum.

Os dados foram coletados e organizados a partir de informações básicas sobre cada coletivo, destacando principalmente o tema e o eixo de atuação. Essa sistematização foi fundamental para desenvolver a análise dos principais eixos temáticos que orientam as ações dos grupos e possibilitou a compreensão da multiplicidade da multidão, conforme a conceituação desenvolvida por Hardt e Negri (2005).

A coleta de informações para o mapeamento dos principais eixos temáticos que caracterizavam a ação dos coletivos do município de São Paulo entre 2011 e 2012 privilegiou uma cartografia das ações para compreender a multiplicidade de reivindicações do webativismo durante aquele período. A etapa posterior da pesquisa consistiu na elaboração de categorias analíticas que embasaram a formulação dos eixos temáticos e a construção dos critérios de análise.

A metodologia utilizada baseou-se no debate sobre o uso das redes digitais, desenvolvido inicialmente por Manuel Castells (2009) na obra Comunicación y poder, na qual o autor apresenta uma tipologia para analisar as formas de organização do poder na sociedade contemporânea, enfatizando a incorporação das tecnologias de informação e de comunicação para a organização de novas práticas sociais e políticas. Articulado à noção de poder em rede formulada por Castells, utilizaremos o conceito de multidão com o objetivo de analisar as formas de atuação dos coletivos de ação cultural e política da contemporaneidade, com base na horizontalidade da organização. Discutiremos centralmente as características gerais que perpassam a ação dos grupos pesquisados por entender que está emergindo um novo momento da organização social e política que, além de usar as redes digitais como espaço de debates e organização das iniciativas, também expressa a configuração da política em rede (Castells, 2009).

A organização dos coletivos analisados pode ser compreendida a partir da análise do processo de transição do uso de práticas políticas tradicionais para novas práticas políticas, aspecto que, segundo Gohn (2014), pode ser entendido a partir da caracterização dos chamados novíssimos movimentos sociais, cabendo destacar o caráter provisório de definições 
desse tipo. Trata-se de um debate complexo, com diversas conceituações, algumas que convergem, outras que se confrontam. Nessa polifonia conceitual veremos, conforme Maria da Glória Gohn, a fragmentação no plano acadêmico para a compreensão das mudanças em curso: "No plano teórico-metodológico conclui-se que não há uma só teoria ou agenda de pesquisa sobre os movimentos sociais, mas múltiplas agendas e teorias. Este fato revela a fragmentação do campo temático em múltiplos sujeitos, em formas híbridas de ações coletivas" (Gohn, Bringel, 2014, p.32).

Embora o artigo não busque uma revisão dos conceitos e teorias sobre os movimentos sociais, consideramos fundamental o esforço de um número significativo de pesquisadores na elaboração de definições mais precisas para a compreensão dos fenômenos trazidos pela atuação dos sujeitos políticos contemporâneos. É importante ressaltar que a menor presença de estruturas hierárquicas nas práticas sociais precisa ser interpretada a partir da compreensão desse processo transitório que testemunhamos atualmente. O novo ativismo surge a partir da articulação das práticas de atores políticos das organizações tradicionais, das redes de coletivos descentralizados com práticas colaborativas e dos grupos que ainda estão sob a influência dos referenciais das configurações verticalizadas nas dinâmicas de discussãoe de deliberação.

Consideramos que estamos vivendo a transição de cultura política baseada nas instituições representativas, na qual as formas de participação dos indivíduos e coletivos ocorrem de maneira mais restrita, para uma forma de participação mais direta, em que a representação tem um papel menos significativo e, muitas vezes, deixa de ter importância à medida que o envolvimento com o debate político e com as questões deliberativas passa a ocupar cada vez mais lugar na política contemporânea. Evidentemente, esse processo pode ser longo e se caracteriza pelo imponderável, imprevisível, ou seja, um processo em aberto que depende das práticas e condutas dos sujeitos que nele atuam.

Nas práticas políticas atuais, é expressivo o aumento da desconfiança nas instituições políticas tradicionais, que já não atenderiam de forma satisfatória às reivindicações dos coletivos políticos e sociais nem às necessidades de incorporação de mais sujeitos nos debates e nos processos políticos decisórios. Estamos atravessando uma crise da forma representativa, característica da democracia moderna, verificando-se no centro dessa crise o distanciamento entre representantes e representados.

É importante destacarmos que o papel desempenhado pelas tecnologias de informação e de comunicação está na ampliação dos espaços de debates sobre questões das mais diversas naturezas. Em nenhum momento anterior, indivíduos e coletivos com poucos recursos financeiros encontravam canais diretos a fim de expressar suas opiniões para uma parcela significativa de pessoas, independente de sua localização territorial, conforme observamos na análise dos coletivos pesquisados. Além da expansão dos espaços de debates e da amplificação das mensagens dos coletivos sociais, verifica-se a transformação da arena política, em que o espaço público passa a ser ocupado, mas com os valores próprios da política em rede, que nos leva à ampliação de formas cooperativas fundamentais para o desenvolvimento da cultura da colaboração - ou do que Michael Hardt e Antonio Negri (2005, p.132) afirmam ser a produção do comum:

Os membros da multidão não precisam tornar-se o mesmo ou abdicar de sua criatividade para se comunicar e cooperar entre eles. Mantêm-se diferentes em termos de 
raça, sexo, sexualidade e assim por diante. O que precisamos entender, portanto, é a inteligência coletiva que pode surgir da comunicação e da cooperação dentro de uma multiplicidade tão variada.

A capacidade de ampliação de interlocutores possibilitada pelas mídias digitais é fundamental, uma vez que amplifica as manifestações de diversos sujeitos sociais, qualificando-os na arena de debates dentro e fora da rede, on-line e off-line. A incorporação de novos sujeitos políticos nos debates vem proporcionando transformações importantes no campo da política e modificando os principais vetores do debate social. Significa dizer que não somente novas questões são introduzidas, mas, sobretudo, é mudado o processo pelo qual elas são incorporadas no debate político.

É fundamental compreendermos a atuação em rede proporcionada pela internet para analisarmos as transformações que estão em curso na configuração dos coletivos sociais e políticos contemporâneos. Em primeiro lugar, nota-se a ampliação das formas de conexão entre indivíduos e entre indivíduos e grupos. Esse aspecto proporciona a horizontalidade da comunicação e, portanto, a ruptura com o elemento característico dos meios de comunicação tradicionais, que se organizavam a partir da relação entre um emissor e muitos receptores. Nesse sentido, a internet favorece, em primeiro lugar, a multiplicidade e a heterogeneidade das conexões, e cada ponto da rede pode realizar conexões infinitas com múltiplos pontos descentralizados, como um movimento turbilhonar na ocupação de espaços e na construção de percursos que estão em constante criação. Na rede, não existe um centro de informação, mas uma multiplicidade que ganha força a cada novo acontecimento.

Para Manuel Castells (2009), as práticas sociais e políticas na rede cada vez mais se misturam e se manifestam no espaço urbano, gerando o que o autor denomina espaço da autonomia, os espaços de fluxos. Aqui, é possível aproximar o pensamento de Manuel Castells ao de Michael Hardt e Antonio Negri (2005). Ambas as reflexões, embora a partir de perspectivas analíticas distintas, abordam a política em rede e na rede como potencializadora do desenvolvimento de novas práticas coletivas. Para Castells, a rede possibilita o desenvolvimento do companheirismo. Para Hardt e Negri, os fluxos comunicacionais favorecem o desenvolvimento de modos de vida cooperativos, baseados no desenvolvimento de dinâmicas centradas no que denominam "comum".

É importante destacar que, além da relação entre on-line e off-line, o uso das redes também nos coloca em simultaneidade, em diálogo constante com o ativismo de várias partes, superando as barreiras identitárias próprias das fronteiras dos Estados nacionais, ampliando formas de interlocução entre coletivos políticos e culturais de vários países, caracterizando, desse modo, as ações políticas em rede. Nesse sentido, Yochai Benkler (2007) aborda a importância das práticas sociais que se utilizam das ferramentas digitais como forma de proporcionar a potencialização da produção social, destacando a conversação e a colaboração abertas como as principais novidades da sociedade da informação. Ignacio Ramonet (2012, p.27) desenvolve concepção que se articula à de Yochai Benckler, conforme observamos na seguinte passagem:

Nós passamos da era das mídias de massa para a era da massa de mídias. Antes, as 'mídias-sol', no centro do sistema, determinavam a gravitação universal da comunicação e da informação em torno delas. Agora, 'mídias-poeira', espalhadas pelo conjunto do sistema, são capazes de se aglutinar para constituir, em certas ocasiões, superplataformas 
midiáticas gigantescas. A lógica do predador solitário é sucedida pela estratégia do enxame (destaques no original).

Para Yochai Benkler (2007), estamos vivendo o deslocamento das formas comunicacionais das mídias massivas, modificando a configuração da opinião pública. Nessas formas, a opinião pública é agendada e enquadrada pelos massmedia; nas novas mídias, ao contrário, prevalece a conversação em rede, que pressupõe diálogos, ação comum e compartilhamento. A conversação se constitui na nova esfera pública que é o ciberespaço, onde a interlocução aberta e livre é base para a ação política.

As mídias pós-massivas, segundo o autor, são mais "conversacionais" que informacionais, considerando que as redes informativas são tecnologicamente interativas e nelas o processo comunicativo depende de interação dialógica e multidirecional entre sujeitos, circuitos, avatares e entidades transorgânicas. Nota-se, portanto, a ênfase nas práticas conectivas de interação entre mente, sujeito, redes, circuitos, informações e inteligências. Entre as transformações geradas na atualidade pelo uso das novas mídias, destacam-se as mudanças que os fluxos informacionais introduzem nos processos democráticos relacionados aos territórios. O autor enfatiza que vivemos numa era de pós-territorialidade na qual o território, bem como a percepção de lugar, são constantemente ressignificados pelas práticas comunicativas, pelos fluxos informativos, pelas imagens e pelos usos das redes.

Nas formas digitais de participação política, a pós-territorialidade é composta por informações que atravessam o espaço e alteram significativamente a percepção dos indivíduos, fazendo com que os significados sociais sejam, cada vez mais, influenciados pelas imagens e pelos territórios imateriais. Os territórios informativos estão em constante alteração, assumindo significados distintos de acordo com os usuários e os tipos de interface utilizados. A utilização das redes digitais, de videocâmeras, fotografias digitais, satélites, entre outros dispositivos, proporciona o acesso às informações em tempo real e vem modificando a pauta de debates das políticas locais que, cada vez mais, buscam a reflexão sobre temas globais como as desigualdades econômicas, o combate à corrupção, os problemas ambientais, questões urbanas, entre outros. Esse tipo de relação entre o local e o global proporciona a ampliação da abordagem de temas que não podem mais ser pensados considerando apenas as perspectivas regionais, visto que estão frequentemente impactados pelos processos globais.

Lemos e Lévy (2010) afirmavam o surgimento de uma filosofia do compartilhamento, possibilitada pelos computadores. Nesse caso, o compartilhamento proporcionado pelas conexões entre diversos grupos, de forma descentralizada, demonstra que a política em rede é capaz de proporcionar novos arranjos sociais e políticos, novas articulações entre sujeitos em busca de práticas mais colaborativas.

O caráter conectivo e interconectivo das redes digitais vêm demonstrando nos últimos anos a potencialização das ações de indivíduos, grupos e coletivos, em âmbito local e global, como demonstrado nas três revoltas ocorridas em 2011: "Primavera árabe" (revoltas em diversos países árabes); 15M (indignados da Espanha); e Ocuppy (EUA). É importante destacar que essas práticas políticas se articulam não somente pelo uso que fazem das mídias digitais, mas pela conexão das temáticas que orientam as ações dos ativistas e, principalmente, pela forma como questionam o efeito das políticas neoliberais na vida contemporânea em decorrência 
do domínio exercido pela lógica de mercado na vida social e política. Nesse sentido, torna-se fundamental afirmar que a crítica realizada pelos ciberpessimistas ${ }^{1}$ sobre a ineficiência das práticas políticas on-line parece estar em descompasso com a atualidade e com as práticas políticas da multidão. Não nos identificamos com essa perspectiva de debate, que coloca em contraposição as práticas políticas desenvolvidas dentro e fora da rede. Trata-se de uma falsa polêmica, apenas para promover uma falsa hierarquia entre os movimentos on-line e off-line. Esse espaço híbrido, conforme afirma Manuel Castells (2013), atua de forma cada vez mais indiscernível, conforme pudemos observar, no Brasil, nos casos do processo de elaboração do Marco Civil da Internet e da Lei da Ficha Limpa, apenas para destacar algumas das mais importantes ações políticas articuladas por meio da rede utilizando plataformas digitais colaborativas.

Outro aspecto importante desse debate é a capilaridade da ação política possibilitada pelo uso das redes sociais, que se apropriam das novas mídias para intervir na conjuntura política do país. O desenvolvimento das novas tecnologias e a possibilidade de criação de redes de comunicação, de interesses específicos, utilizando os mais variados recursos, meios e canais são fundamentais. O ciberespaço oferece um conjunto diversificado de informações que circulam entre os grupos, ativismos compartilhados e hipertextos comunitários para a constituição de coletivos de cibercultura e ciberpolítica. A produção coletiva de conhecimento na rede é notoriamente reconhecida como um dos pilares da inteligência coletiva e utilizada como referência para as mais variadas correntes midiáticas - ecoando nas mais diversas áreas de conhecimento humano, como a filosofia, a tecnologia da informação, a cognição e a sociologia.

$\mathrm{O}$ advento da internet possibilitou que as relações sociais cotidianas fossem construídas no ciberespaço, incluindo aí os coletivos e o ativismo político. Essa chamada revolução tecnológica é caracterizada por Manuel Castells (1999, p.69) não pela "centralidade de conhecimentos e informação, mas pela aplicação desses conhecimentos e dessa informação para a geração de conhecimentos e de dispositivos de processamento/comunicação da informação, em um ciclo de realimentação cumulativo entre a inovação e seu uso".

Dessa forma, os coletivos de ação social e política se utilizam da internet e de sua velocidade de transmissão de informações como algo estratégico para a sua atuação. Manuel Castells $(2009$, p.394) afirma que os movimentos sociais são atores que visam às mudanças culturais e de valores éticos.

Os atores sociais que aspiram à mudança cultural (mudança de valores) conceitualizo como 'movimentos sociais' e os processos que aspiram à mudança política (mudança institucional) em descontinuidade com a lógica incorporada nas instituições políticas os defino como políticas insurgentes (destaques no original). ${ }^{2}$

Para Lemos e Lévy (2010, p.130),

o desenvolvimento das comunidades virtuais se apoia na interconexão. Uma comunidade virtual é construída sobre as afinidades de interesses, de conhecimentos, sobre projetos mútuos, em um processo de cooperação ou de troca, tudo isso independentemente das proximidades geográficas e das filiações institucionais.

Concordamos com Quintana e Tascon (2012, p.256) quando afirmam que "é necessário pensar nos protestos como processos em que não há um criador. E nos quais nem tudo tem 
que resultar em um produto". Portanto, trata-se de reconhecer a importância dos processos de articulação política, independente das conquistas reais, apesar de essas serem importantes. É fundamental reconhecer que um conjunto de práticas políticas cumpre o papel de impulsionar transformações significativas nas dinâmicas de poder e pode levar a um processo de potencialização dos sujeitos sociais e coletivos, modificando desse modo as estruturas de poder.

A redefinição do poder na sociedade em rede é fundamental para compreender em que medida estamos atravessando uma transformação nas práticas políticas, bem como nas dinâmicas de poder na contemporaneidade. Manuel Castells $(2009$, p.81) enfatiza que essas transformações são impactadas pela incorporação dos dispositivos informacionais nas articulações políticas.

Na sociedade em rede $O$ poder está redefinido, mas não desapareceu. Como também não desapareceram os conflitos sociais. A dominação e a resistência à dominação mudam de caráter segundo a estrutura social específica em que se originam e que modificam com sua ação. O poder governa, O contrapoder combate. As redes processam SEUS programas contraditórios enquanto as pessoas tentam encontrar sentido frente a SEUS medos e SUAS esperanças.

Para o autor, existem quatro formas distintas de se pensar o poder nas redes. A primeira seria o networking power, considerado o poder de se conectar em rede na sociedade global. É o poder dos atores e organizações incluídos nas redes sobre os coletivos ou indivíduos que não estão nelas incluídos. Castells identifica o que chama de gatekeeping, que seriam os filtros que expressam o poder coletivo de algumas redes sobre outras. Outra forma de poder é o networker power, ou o poder na rede. Significa que os mecanismos básicos para o exercício do controle do poder no mundo da rede requerem a capacidade de construir e de reprogramar as redes, além da capacidade para conectar diferentes redes, o que pode proporcionar a cooperação e o compartilhamento de objetivos e de recursos. Destaca também o que denomina networkmaking power, entendido como o poder de criar redes. Essa talvez seja uma das formas mais verificadas nas práticas políticas interconectadas, considerando as amplas possibilidades de conexão entre indivíduos e coletivos em torno de ações políticas locais ou globais.

$\mathrm{Na}$ análise das ações dos coletivos pesquisados verificamos essas categorias elaboradas por Castells. Alguns coletivos demonstraram estar em consonância com coletivos de outras redes e expressaram sua capacidade de influir no debate ou na organização de uma determinada ação que interconectasse diversos coletivos. Podem ser chamados de "autoridade de rede"3 pela forma como são capazes de ser referências dentro de um debate na rede, considerando o tema que orienta suas ações. Outros coletivos exercem papel importante na criação de redes (network-making power). Nesse sentido, os temas que orientam a ação política e cultural dos coletivos desempenham um papel fundamental uma vez que os coletivos podem constituir redes pontuais, capazes de articular ativistas em torno de ações específicas, podendo a rede, posteriormente, ser desarticulada. Essa é uma prática comum verificada nos eventos organizados pelo Facebook.

Dessa maneira, nota-se claramente o constante uso de ferramentas digitais nas ações em rede por meio das comunidades virtuais interconectadas. Porém, as ações não são necessariamente dependentes apenas dos mecanismos virtuais de ativismo, mas os utilizam como estratégia, de modo que, como cita Manuel Castells (1999, p.444; destaques no original), "as 'comunidades 
virtuais' não precisam opor-se às 'comunidades físicas': são formas diferentes de comunidade, com leis e dinâmicas especificas que interagem com outras formas de comunidade".

As ações políticas digitais promovem o aumento de instrumentos, meios e oportunidades para que as minorias políticas se representem e sejam representadas na esfera pública e nas instâncias de produção da decisão política, sendo fundamentais para o processo de potencialização da democracia contemporânea. A cibercultura seria responsável por impulsionar a ciberdemocracia possibilitada pela interconexão das comunidades e pela construção da inteligência coletiva (Lemos, Lévy, 2010). A ciberdemocracia começa a ser verificada à medida que se assegura acesso às informações governamentais, propiciando a condução de projetos-pilotos na área de consultas públicas em meio eletrônico e contribuindo para ajustar formalmente os processos políticos, operando mudanças na legislação e nas instituições.

\section{A ação política da multidão}

Ao analisarmos os coletivos de ciberpolítica e cibercultura de São Paulo nos deparamos com uma característica central dessas novas formas de organização social e política que se caracteriza pela multiplicidade de temas e de agendas que orientam as ações políticas dos referidos grupos. Essa característica está em consonância com as práticas políticas que Hardt e Negri (2005) identificam na multidão.

As características das práticas políticas atuais, segundo esses autores, diferenciam a multidão da categoria tradicional de povo. Este era entendido como uma unidade que atua em torno de eixos centrais, ao passo que a multidão caracteriza-se justamente pela multiplicidade, pela pluralidade. Essa característica se manifesta na diversidade de temas que orientam as ações dos coletivos e grupos que compõem a multidão. O conceito de povo corresponde à forma de soberania produzida na modernidade, na qual o soberano era o único capaz de evitar o caos ou o estado de guerra vivido pela multidão. Ao soberano cabia dissolver a multiplicidade da multidão para unificá-la no conceito de povo. Hobbes (1988, p.105-106) foi um dos principais autores a defender esse tipo de concepção, conforme podemos observar em sua obra O Leviatã:

Cedo e transfiro meu direito de governar-me a mim mesmo a este homem, ou a esta assembleia de homens, com a condição de transferires a ele teu direito, autorizando de maneira semelhante todas as suas ações. Feito isto, à multidão assim unida numa só pessoa se chama Estado, em latim civitas. É esta a geração daquele grande leviatã, ou antes (para falar em termos mais relevantes) daquele Deus Mortal, ao qual devemos abaixo do Deus Imortal, a nossa paz e defesa. Pois graças a esta autoridade que lhe é dada por cada indivíduo no Estado, é-lhe conferido o uso de tamanho poder e força que o terror assim inspirado o torna capaz de confrontar as vontades de todos eles, no sentido da paz em seu próprio país, e da ajuda mútua contra os inimigos estrangeiros. É nele que consiste a essência do Estado, a qual pode ser assim definida: uma pessoa de cujos atos uma grande multidão, mediante de pactos recíprocos uns com os outros foi instituída por cada um como autora, de modo a ela poder usar a força e os recursos de todos, da maneira que considerar conveniente, para assegurar a paz e a defesa comum.

Essa noção foi fundamental para a forma de soberania do Estado moderno, principalmente a partir do final do século XVIII até meados do século XX. Nas últimas décadas do século 
XX, começamos a observar a emergência de movimentos que expressam a retomada da multidão, provocando o deslocamento da noção de povo como forma manipulável pelas dinâmicas políticas tradicionais. As formas identitárias começavam a dar lugar às expressões singulares e a desarticular a massa homogênea. Esse processo está em consonância com a contemporaneidade, à medida que verificamos, nas últimas décadas, um questionamento às formas representativas, conforme analisamos nos temas que nortearam as ações dos coletivos de cibercultura e ciberpolítica estudados no eixo temático que abordou a crítica à política.

Dito de outro modo, o conceito de povo é intrinsicamente vinculado aos procedimentos representativos. O povo sempre é representado como uma unidade que atua de forma homogênea. Diferentemente da multidão, que não é representável, conforme o conceito de Hardt e Negri (2005), considerando que ela é composta por uma multiplicidade de sujeitos, com demandas e ações diversificadas.

A multidão também se diferencia das noções de massa e plebe, frequentemente associadas a uma força social considerada perigosa, irracional, passiva e facilmente manipulada. Conforme observamos na atuação dos coletivos pesquisados, não há uma passividade na ação desses grupos; ao contrário, são protagonistas, sujeitos sociais cuja ação é propositiva, crítica e organizada, embora muitas vezes seja considerada dispersa pelo fato de ser heterogênea devido à multiplicidade de temas que compõem suas práticas sociais e políticas.

Outro aspecto fundamental para compreender a potência da multidão é a contextualização do conjunto de transformações ocorridas na sociedade contemporânea e, mais especificamente, no âmbito da produção e reprodução de riquezas, cujas mudanças impactam não somente na forma de produzir bens materiais e imateriais, mas principalmente na produção da subjetividade contemporânea.

A reestruturação produtiva e a passagem do fordismo para o pós-fordismo pode ser caracterizada, entre outros aspectos, pela maneira como os elementos cognitivos passam a ser essenciais na produção e expressam o papel que a subjetividade passou a ocupar nos processos produtivos, principalmente a partir dos anos 1970. Hardt e Negri (2005), entre outros autores, retomam uma obra fundamental de Karl Marx, os Grundrisse, escrita entre 1857 e 1858, na qual o autor já destacava a importância das questões subjetivas para o processo produtivo. Desde o final da década de 1960, Negri se dedicou a estudar os Grundrisse para encontrar na reflexão de Marx o fundamento para a elaboração de uma teoria de desenvolvimento da subjetividade proletária ou a definição do sujeito revolucionário. A noção de general intellect pode ser sintetizada na articulação dos dispositivos tecnológicos ao conhecimento social, uma subjetividade social que conjuga a força produtiva e as formas organizativas dos indivíduos.

A análise da passagem do fordismo para o pós-fordismo destacava o papel que a dimensão intelectual do trabalho adquire na atual configuração da empresa reestruturada, o que significa dizer que "é a alma do operário que deve descer na oficina" (Negri, 2001, p.25). Essa expressão contribui para compreender que um dos elementos fundamentais da reestruturação produtiva é a mudança do caráter material para o imaterial da produção. O trabalhador do novo modelo produtivo desempenha o trabalho de gestão da informação e capacidade de tomar decisões. Portanto, o trabalho operário se tornou atividade abstrata ligada à subjetividade, a própria manifestação do general intellect. É nesse sentido que teremos um novo sujeito político, ancorado no trabalho imaterial, cuja base é a subjetividade individual e coletiva. Esse sujeito 
é a multidão que, para Hardt e Negri (2005), tem a capacidade do verdadeiro exercício de um antipoder, do exercício de uma democracia absoluta que conjuga simultaneamente resistência, insurreição e poder constituinte.

Embasados no conceito spinoziano de democracia absoluta, vemos que apenas a resistência é insuficiente para se criar um antipoder. A multidão é entendida como única força política imanente capaz de acionar e manter as dinâmicas de antipoder resistentes às formas burocratizadas, características da democracia representativa. A representação é vista como obstáculo à democracia por impedir a expressão da potência política dos indivíduos. Spinoza, filósofo do século XVII, exerce forte influência no pensamento de Hardt e Negri (2005) e tem sido retomado também por outros autores com o objetivo de contribuir para novas leituras a respeito da potência do sujeito social capaz de incidir no processo de transformação dos processos políticos.

O deslocamento e a valorização da imanência no processo político fez com que os autores repensassem a noção de biopolítica desenvolvida por Michel Foucault, que era vista como a forma de governar a vida a partir da gestão da saúde, da natalidade, sexualidade, alimentação, entre outras esferas que, a partir do final do século XVIII, se tornaram preocupações de Estado, dentro da racionalidade política liberal.

Nesse sentido,

Precisamos pensar a biopolítica como conjunto de biopoderes que derivam da atividade de governo, ou, pelo contrário, na medida em que o poder investiu a vida, a vida também se torna um poder? Ou melhor, podemos dizer que a biopolítica representa um poder que se expressa pela própria vida, não somente no trabalho e na linguagem, mas também nos corpos, nos afetos, nos desejos, na sexualidade? Podemos identificar, na vida, o lugar de emergência de uma espécie de antipoder, de uma potência, de uma produção de subjetividade que se dá como momento de dessujeição? Nesta segunda perspectiva interpretativa, sempre que a vida se apresentasse como potência, o tema da biopolítica seria fundamental para uma reformulação da relação política: a biopolítica representaria a passagem do político ao ético, ou ainda, uma perspectiva de construção ética do corpo, da vida dos prazeres e da vida do trabalho. Em 1982, Foucault sustentava que a análise da população, o questionamento das relações de poder e do antagonismo entre relações de poder e a afirmação de intransitividade da liberdade constituem uma tarefa contínua. É lá, nessa abertura intransitiva da liberdade contra toda máquina, contra toda estrutura de poder, que se estabelece a tarefa política inerente a cada existência social. Esse é, pois o conceito de biopolítica que caracteriza as últimas análises de Foucault (Negri, 2003, p.106).

Hardt e Negri (2005) entendem a biopolítica como uma rede possibilitadora de atividades dos indivíduos capazes de construir, de forma singular, dentro de um campo de acontecimentos sociais entrelaçados por um conjunto de narrativas que se utilizam de imagens, vídeo e ferramentas digitais. A partir dessa compreensão, a biopolítica da rede é capaz de potencializar as práticas sociais e políticas e fazer emergir um novo sujeito social, que é a multidão. Segundo os autores, a multidão é o proletariado contemporâneo. A configuração da multidão ocorre quando um acontecimento coloca em contato grupos de atuações diversificadas que se articulam e promovem uma convergência em suas atuações. Essa convergência ocorre tanto da perspectiva de usos de diversas ferramentas midiáticas como também do ponto de vista 
estratégico da atuação da multidão e da ocupação dos espaços públicos. A análise realizada sobre a ação dos coletivos de ciberbiopolítica e cibercultura expressa o caráter germinativo da multidão.

\section{Política e crítica à política}

Esse eixo temático foi composto a partir da identificação das ações que caracterizam os coletivos analisados. Nesse sentido, verifica-se que o conjunto de temas que norteava a ação política era bastante heterogêneo, assim como era grande a diversidade de posicionamentos expressos em torno dos temas debatidos. Em alguns casos, o tema orienta uma ação política para a mobilização social e se desloca do espaço on-line para o off-line; em outros, se restringe à expressão de opiniões, sem o objetivo de organizar uma ação, mas apenas discutir questões relacionadas à política ou críticas à política.

A crítica à política pode ser entendida como aperfeiçoamento institucional, sob a forma de cobrança do papel das instituições, mas também é expressivo o número de postagens que criticam a atuação dos políticos, principalmente em relação às denúncias de corrupção. O combate à corrupção aparece como salvação da política e como forma de solucionar os problemas da gestão pública. Por outro lado, verifica-se também que a crítica não se destinava ao aperfeiçoamento das instituições e aos procedimentos da política, mas se inseria na perspectiva da ruptura com os modelos tradicionais da política, estando em consonância com os movimentos globais do período, tais como Democracia Real da Espanha. Trata-se, no geral, de debate colocado a partir da perspectiva de grupos de orientação anarquista ou libertária, que afirmam a impossibilidade de aperfeiçoamento institucional e criticam as reformas por achar que são insuficientes para a solução dos problemas políticos do país.

Considerando que o período da análise dos coletivos selecionados foi 2012, ano em que se realizaram as eleições municipais no país, alguns coletivos, de orientação anarquista, criticavam a própria existência de eleições, tratando-as como um processo que reforça a democracia representativa e faz com que a participação, a ação direta, seja deixada em segundo plano. Nesse sentido, as eleições municipais eram criticadas por ser a expressão do que consideram uma farsa política.

O questionamento ou apoio aos políticos também estava presente, no sentido de repúdio tanto à política tradicional quanto às formas verticalizadas próprias das estruturas partidárias, sindical e dos movimentos políticos tradicionais. Nesse sentido, o discurso frequente é o da necessidade de criação de novas formas de organização social e política baseadas na horizontalidade; na quebra da centralização dos debates, realizada pelas lideranças; e no exercício da democracia direta, que traz a possibilidade de incorporar mais sujeitos políticos nos processos deliberativos e, portanto, de ampliar a participação política da sociedade.

A crítica à cobrança de impostos no país também foi abordada e, frequentemente, esteve associada ao questionamento do uso dos recursos públicos, à falta de investimento em infraestrutura e em serviços públicos, como rede pública de saúde e educação de qualidade. Essa crítica também foi articulada ao debate em torno da corrupção e dos escândalos envolvendo políticos influentes de diversos partidos brasileiros. 
Vale lembrar que a defesa e o repúdio das práticas de tortura adotadas durante a ditadura (1964-1985) voltou a ocupar espaço no debate político por causa da atuação das Comissões da Verdade instaladas no país. A discussão em torno dos direitos humanos colocou esse debate na agenda novamente, e seu resgate provocou manifestações favoráveis e contrárias à atuação da Comissão. A repercussão nas mídias tradicionais e digitais vem possibilitando à sociedade civil o enfrentamento desse tema, ainda pouco esclarecido na história do país, mobilizando ideias de orientação conservadora e reformistas nesse processo.

Ainda dentro desse eixo temático, o uso do humor foi recurso amplamente utilizado por diversos coletivos para criticar as práticas políticas tradicionais. Por meio de vídeos, charges e textos, verificou-se o intenso uso da estética para debates essenciais da política brasileira e internacional, cujo discurso se distancia de análises embasadas na racionalidade que envolve o debate político, optando-se pelo deboche, pela ironia, para fundamentar a crítica.

\section{Lutas urbanas}

O debate e a organização de mobilizações em torno das precárias condições de vida no município de São Paulo estiveram no centro da ação política e cultural de diversos coletivos da cidade. A mobilidade urbana foi um dos principais temas em torno do qual os coletivos que atuavam no período da coleta de informações foram muito ativos em junho de 2013, período conhecido como "Jornadas de junho". Embora a pesquisa tenha centrado a análise entre 2011 e 2012, é importante destacar que as manifestações ocorridas em junho de 2013 foram fruto de um processo de mobilizações desenvolvidas durante os anos anteriores.

Os problemas enfrentados na mobilidade urbana estiveram entre os que mais afetaram os paulistanos, e a emergência desses coletivos expressa essa preocupação. A qualidade e o custo do transporte público foram alvos de duras críticas.

Os problemas de moradia também foram debatidos, assim como a tentativa de solucionar o deficit habitacional da cidade, e se observa a crítica à política imobiliária que beneficiaria o mercado imobiliário em detrimento da oferta de moradia digna a preços acessíveis. Esse tema contou com o crescimento de movimentos de sem-teto, que se utilizaram da estratégia da ocupação de prédios públicos ou particulares desocupados como forma de explicitar a dicotomia existente entre edifícios vazios e, muitas vezes, à espera de valorização no mercado imobiliário, em detrimento de um conjunto expressivo de pessoas que não têm condições de acesso a uma moradia digna.

\section{Questões ambientais}

As questões ambientais também ocuparam o centro da atuação de coletivos da cidade de São Paulo. De acordo com as características do próprio debate, verifica-se a existência de campanhas de abrangência nacional, tais como a campanha para o veto de alguns itens do Projeto de Código Ambiental, considerado permissivo pelos coletivos, uma vez que legalizava o desmatamento em áreas ambientais importantes.

Chamou atenção a existência de alguns coletivos ligados à defesa de rios não somente localizados no município de São Paulo, mas no estado como um todo. Trata-se de grupos 
bastante estruturados, com grau de informação técnica sobre o problema da morte de rios, e que atuam basicamente nas redes, embora tenham organizado, episodicamente, atividades públicas.

A defesa da qualidade do ar foi tema de destaque nos grupos que atuaram em torno da temática ambiental. Em alguns casos específicos, os grupos ambientais atuaram em rede com os grupos de mobilidade urbana, enfatizando a necessidade de estratégias governamentais para a mobilidade urbana capazes de diminuir os impactos ambientais gerados pelo excesso de veículos individuais em detrimento da oferta de transporte público de qualidade.

A ação dos coletivos analisados nos eixos temáticos de "lutas urbanas" e "questões ambientais" colocaram temas difusos em torno da questão central: o direito à cidade. Direitos relacionados à moradia, à mobilidade urbana, acesso à cultura, qualidade do ar e da água, entre muitos outros. Não há homogeneidade na rede, considerando que "um mundo interconectado não é necessariamente um mundo homogêneo" (Lévy, 2001, p.30).

Ao usarem as mídias digitais, os coletivos estavam totalmente em consonância com a ocupação do espaço público. A retomada desse espaço foi debatida simultaneamente nos ambientes on-line e off-line. Ou seja, a tomada do espaço público alimenta a organização nas redes e pelas redes.

As cidades são o principal local onde se dá a reprodução da força de trabalho. Nem toda melhoria das condições de vida é acessível com melhores salários ou com melhor distribuição de renda. Boas condições de vida dependem, frequentemente, de políticas públicas urbanas - transporte, moradia, saneamento, educação, saúde, lazer, iluminação pública, coleta de lixo, segurança. Ou seja, a cidade não fornece apenas o lugar, o suporte ou o chão para essa reprodução social. Suas características e até mesmo forma como se realizam fazem a diferença (Maricato, 2013, p.20).

\section{Movimentos culturais}

Os movimentos culturais são muito ativos na rede, e suas ações estão na fronteira entre a cibercultura e a ciberpolítica. Significa dizer que as práticas culturais estão permeadas por críticas, tanto à ausência ou insuficiência de políticas culturais para abarcar a multiplicidade da produção cultural do município de São Paulo quanto aos grupos que se utilizam de práticas culturais para o questionamento da política.

Esses movimentos apresentaram uma questão relevante ao afirmar que a arte e a cultura contemporânea exercem um papel eminentemente político. A forma, a linguagem, a estética podem ser diversificadas: teatro, cinema, música, grafite, enfim, independente da forma, o que caracteriza a ação desses coletivos é que estão em consonância com os problemas da metrópole, e seus atos se constituem como forma de intervenção na dinâmica cultural e política da cidade. Também atuavam em rede e utilizavam a prática colaborativa tanto para a elaboração da ação desenvolvida quanto para financiar shows, espetáculos teatrais ou circenses, mostra de vídeos e de fotografias etc.

Rheingold (2002) trabalha com a emergência da ideia de uma cultura colaborativa que, além de ser pensada para analisar a atuação dos novos movimentos sociais, também nos ajuda a compreender em que medida o compartilhamento de saberes é fundamental para 
o processo de formação no novo ethos social que refuta as práticas políticas tradicionais e também as formas de produção e disseminação do conhecimento, como podemos observar nas práticas de copyleft, questionadoras da propriedade intelectual e o crowdfunding, prática de financiamento coletivo que se utiliza da colaboração dos indivíduos e não de empresas, ou do Estado, para a realização de atividades culturais, por exemplo.

Trata-se de pensar a partir de uma multiplicidade de atores cuja ação se desenvolve simultaneamente em diferentes formas de inserção social, sem uma liderança política definida, conforme se verifica nas formas de organização social hierarquizadas, tais como partidos políticos, sindicatos, entre outros. Verifica-se uma nova forma de fazer política pautada em uma dinâmica mais horizontalizada e com o que chamaremos provisoriamente de sujeitos protagonistas inseridos nos debates em torno das questões sociais e que usam as redes digitais para o processo de articulação das lutas sociais.

Não cabe aqui abordar o debate em torno dos conceitos de ciberpolítica e cibercultura, considerando as diferentes perspectivas temáticas e teóricas. ${ }^{4}$ De maneira mais ampla, adotamos a definição mais consensual que orientou o trabalho empírico realizado para essa pesquisa. A noção de ciberpolítica adotada se refere ao sentido dos impactos trazidos pelas novas tecnologias digitais sobre a ação política, ou seja, as influências exercidas nos sistemas políticos, nas instituições políticas, bem como a criação de novos espaços de participação e deliberação proporcionados pelo uso das tecnologias de informação e de comunicação. Trata-se da política ciberneticamente mediada.

A cibercultura se dedica a analisar o surgimento de identidades coletivas capazes de articular processos de criação simbólica e promover a interação entre diferentes atores sociais, conforme observamos na reflexão de Rudiger (2011). O ciberativismo também se utiliza do uso de tecnologias de comunicação para a realização de ações coletivas que visem à ampliação da cidadania. Para esse percurso utilizaremos mais diretamente as reflexões desenvolvidas por Manuel Castells, Francisco Rüdiger, bem como Pierre Lévy, que trabalhou conjuntamente com o sociólogo brasileiro André Lemos.

A noção de cibercultura é abordada a partir da problematização de Rudiger (2011, p.59), que afirma:

o conceito de cibercultura, menos que um construto simbólico a ser descartado, deveria continuar a ser pensado, mas criticamente, como sinal de um problema, que é o das condições de formação do indivíduo no que seria, reflexivamente, um estágio avançado da indústria cultural convertida em sistema. A reflexão sobre suas manifestações nos fornece várias razões para crer que os espaços para elaborar conhecimento, em vez de meramente receber informações, e efetivamente desenvolver uma formação individual, em vez de meramente interagir à distância com os demais, oferecidos via internet são muito limitados... A cibercultura se movimenta sobre o pano de fundo da paulatina expansão do mundo da informática e, por tudo o que dissemos, em vez de o fazer como meio de elaborar o sentido da experiência vivida, pode ser que, antes, atue como enorme formação reativa ou mecanismo de defesa aos efeitos perversos do projeto de domínio do mundo e recriação artificial da existência contidos, sob as condições da economia de mercado total, naquela expansão. 


\section{Grupos minoritários}

Adotamos o conceito de grupos minoritários a partir da noção deleuziana de menoridade, ou de minoritário, que não significa ter um valor diminuído diante daquilo que é maior ou que é dominante, mas que se refere a grupos que não estão contemplados, ou estão sub-representados no sistema representativo vigente (Deleuze, Guattari, 1977). Trata-se, portanto, de grupos que estão em posição assujeitada, subjugada nas relações sociais em que estão inseridos. Os povos indígenas se enquadram nessa concepção de grupos minoritários, considerando que seus direitos, principalmente nas aldeias urbanas como as encontradas nessa pesquisa, não oferecem condições satisfatórias para o desenvolvimento de seus modos de vida, práticas culturais e rituais. Incrustados em regiões periféricas da cidade, essas populações enfrentam muitas dificuldades e contam com solidariedade de grupos sociais que desenvolvem ações colaborativas para despertar a atenção para a gravidade da situação dos chamados povos da floresta.

O racismo também foi tema de debates polêmicos nas redes sociais. Verificamos que, apesar de ser considerado crime hediondo, o preconceito em relação à população negra é frequente e tem sido denunciado e debatido pelos coletivos afrodescendentes, que consideram necessário um amplo processo de discussão social sobre o tema, tendo em vista que as práticas racistas condicionam o pensamento e as ideias que norteiam a sociabilidade dos indivíduos nas instituições sociais.

Os ataques aos moradores de rua foram denunciados por vários coletivos, embora não tenhamos identificado nenhum coletivo que trabalhe especificamente com essa temática. Questões como a ação do poder público, seja policial, ou até mesmo da assistência social, são identificadas como prática higienista, e, segundo as manifestações de alguns coletivos, deve ser debatida para que se diminua o preconceito com essa população. É frequente nas redes sociais que temas que ganham visibilidade por ações ocorridas nas ruas, nas práticas off-line, tornem-se temas de discussão e, algumas vezes, até mesmo de campanhas nas redes. Verificamos que a rede é utilizada para problematizar o tipo de visibilidade que os meios de comunicação de massa constroem dos moradores de rua e para abrir canal para outra perspectiva de pensar os modos de vida dessa população.

Os grupos homossexuais também usaram a rede para sua organização e tiveram um papel ativo durante o período analisado, principalmente pelos ataques de grupos religiosos conservadores que buscam enquadrar o homossexualismo como doença ou desvio de comportamento. Também são alvo de debates e campanhas homofóbicas que, em alguns momentos, misturam-se a determinadas práticas religiosas. A intolerância à diversidade sexual é tema que preocupa alguns coletivos que buscam dar visibilidade às reivindicações como estratégia para serem alcançados direitos sociais

\section{Gênero}

Apesar de a atuação desses grupamentos estar diretamente vinculada aos grupos minoritários, o aspecto de gênero é o que define as práticas de coletivos, por isso optamos pela análise como um eixo temático específico. Verifica-se um uso intenso das redes sociais 
nas campanhas de combate à violência doméstica, mas também há manifestações no sentido de colocar na agenda de debates a importância das mudanças de valor da questão de gênero na sociedade atual.

Embora tenham ocorrido avanços no trato dessas questões, os grupos denunciam formas, mesmo que veladas, de discriminação e utilizam a rede tanto para campanhas de denúncia quanto para a organização de manifestações públicas.

O aborto também foi amplamente debatido na rede, especialmente em alguns momentos específicos, como durante o processo eleitoral de 2012, momento em que o tema estava presente nos debates das candidaturas. Verificou-se o aumento do número de manifestações sobre o tema, tanto de grupos e indivíduos contrários quanto favoráveis à legalização ou à descriminalização. Em torno da discussão de direito ao corpo e à saúde, grupos feministas usam as mídias digitais para campanhas de defesa e de esclarecimento sobre o aborto, além de demonstrar que se trata de um problema de saúde pública, visto que grande número de mulheres morre ou apresenta sequelas em decorrência de abortos realizados clandestinamente e em condições inadequadas.

É importante esclarecer que, apesar de a comunicação em rede potencializar formas de participação social e política, essa fase transitóriade uma democracia representativa para uma democracia participativa não apresenta somente efeitos positivos. Muitas vezes, vemos as redes digitais sendo utilizadas também por grupos que se distanciam das formas colaborativas, ocupando a internet pela ampliação de visibilidade que ela proporciona, podendo incluir valores que reforçam preconceitos homofóbicos, machistas, sexistas, reacionários, alimentando tendências retrógradas da sociedade.

\section{Drogas}

O debate em torno da legalização da maconha ganhou repercussão nas redes sociais nos últimos anos, e o Brasil é um dos países que integram as atividades organizadas em âmbito mundial sobre o tema. Os grupos usam as redes para a organização de discussões em torno dos impactos da legalização das drogas, divulgação de estudos sobre os efeitos da maconha nos usuários e para organizar atividades públicas.

A "Marcha da maconha", evento realizado anualmente em várias partes do mundo, também é organizada no Brasil e, a cada ano, vem diversificando o perfil de manifestantes, não se restringindo apenas aos usuários para os chamados fins lúdicos, mas também em apoio à liberação do princípio ativo da cannabis para fins terapêuticos e industriais, conforme já ocorre em outros países. É o maior evento em torno do tema, totalmente organizado pelas redes; além disso, existem coletivos que realizam ao longo do ano palestras, ciclo de filmes, debates com estudiosos de diversas áreas, incluindo a segurança pública, sobre os benefícios sociais que podem ser gerados com o processo de descriminalização e de legalização da maconha.

\section{Movimento estudantil}

Os grupos que se articulam em torno das reivindicações estudantis ocupam com muita frequência as redes sociais. Além de grupos de instituições de ensino específicas, há também 
aqueles que questionam as práticas políticas adotadas pelas entidades estadual e nacional de estudantes. O questionamento, frequentemente, aponta a vinculação dessas entidades aos partidos políticos e à falta de transparência e de democracia na condução dessas instituições.

Durante o período pesquisado, foi possível acompanhar nas redes sociais páginas específicas de greve realizada no período por estudantes da Universidade de São Paulo e da Pontifícia Universidade Católica de São Paulo, com reivindicações próprias dessas instituições.

\section{Democratização das mídias}

A internet é ferramenta intensamente utilizada pelos coletivos que atuam em torno da democratização das mídias. Historicamente, os coletivos foram os primeiros a adotar a internet em suas práticas políticas, incorporando as ferramentas digitais tanto para a ampliação do debate sobre a importância do direito à comunicação e a garantia da liberdade de expressão quanto para articulação de mobilizações cujo eixo é a comunicação. De maneira geral, trata-se de grupos que atuam em conjunto com outros coletivos de cibercultura e ciberpolítica, conforme observado, por exemplo, nas "Jornadas de junho" de 2013. Esses coletivos também utilizam diversas ferramentas digitais para a mobilização política, como no uso das petições on-line e no processo de elaboração do Marco Civil da Internet, produzido por meio de plataforma colaborativa criada pelo Ministério da Justiça, que contou com a participação de grupos de democratização dos meios de comunicação, além de outros setores da sociedade.

Considerando que o uso das tecnologias de informação, comunicação e conexão já está incorporado às ações sociais e políticas da contemporaneidade, nota-se que a diversificação desse uso expressa a forma como os atores políticos estão dinamizando suas práticas e encontrando nas ferramentas digitais um aliado para potencializar e inovar as formas organizativas. A convergência midiática está para além da apropriação tecnológica, mas articula diversas mídias que podem provocar fatos políticos capazes de colocar debates específicos nas agendas locais e global. Exemplo dessa potencialidade é a divulgação de vídeos amadores, com imagens captadas por aparelhos celulares, o que contribui para divulgar imagens de protestos, difundindo cenas que os grandes meios de comunicação não costumam disseminar, conforme observamos no levantamento dos grupos webativistas do município de São Paulo.

Para Henry Jenkins (2008), a convergência das mídias inaugura um novo paradigma que promove a interação entre as novas e as antigas mídias. Esse paradigma desconstrói a concepção ultrapassada baseada na ideia de que as novas mídias substituíram as antigas. A convergência pressupõe um processo tecnológico que unifica múltiplas funções em um mesmo aparelho, ampliando suas possibilidades de uso.

Lembrem-se disto: a convergência refere-se a um processo, não a um ponto final. Não haverá uma caixa preta que controlará o fluxo midiático para dentro de nossas casas. Graças à proliferação de canais e à portabilidade das novas tecnologias de informática e telecomunicações, estamos entrando numa era em que haverá mídias em todos os lugares. A convergência não é algo que vai acontecer um dia, quando tivermos banda larga suficiente ou quando descobrirmos a configuração correta dos aparelhos. Prontos ou não, já estamos vivendo numa cultura de convergência. Nossos telefones celulares 
não são apenas aparelhos de telecomunicações; eles também nos permitem jogar, baixar informações da internet, tirar e enviar fotografias ou mensagens de textos (Jenkins, 2008, p.41).

\section{Considerações finais}

Observamos que os coletivos pesquisados se organizaram utilizando os perfis das redes sociais (social networking sites), apresentando questionamentos sobre as formas tradicionais de organização da ação política, tais como partidos, movimentos sociais e sindicatos.

O uso das tecnologias de informação e de comunicação para a ação política é considerado fundamental na prática política dos coletivos analisados. Nesse caso específico, constatamos que não se trata apenas do uso comunicacional, mas a própria arquitetura em rede dessas mídias expressa uma modificação no processo político, considerando o caráter horizontal, sem centralização, as formas interativas e, principalmente, o aspecto conectivo entre os coletivos políticos.

A incorporação de ferramentas digitais nos processos políticos proporciona um conjunto de mudanças nos espaços tradicionais de discussão, nas instâncias de formulação e de deliberação, possibilitando a inovação nas formas de participação dos atores.

Verificamos também a utilização de dispositivos digitais e virtuais na articulação de redes sociais com o objetivo de dinamizar e descentralizar o debate político, de ampliar as possibilidades de organização das ações coletivas e de processos de resistência, incorporando os sujeitos aos debates sobre as questões sociais e políticas, expressando, assim, a própria configuração da multiplicidade da multidão. Observamos que as redes sociais potencializam o processo de articulação de determinadas demandas do campo social e podem catalisar sentimentos de protesto ou de indignação em algumas convocatórias, demonstrando uma capacidade que há muito os partidos políticos e movimentos sociais tradicionais vêm perdendo. Temas considerados periféricos na agenda de debates ou até mesmo que envolvem questões relacionadas às políticas públicas ganham outro tratamento, uma abordagem que se difere das formas utilizadas pelos movimentos sociais tradicionais.

Em síntese, os coletivos estão buscando formas de organização de suas ações diferentes das praticadas pelos chamados movimentos sociais. Esse é o processo que estamos atravessando, que se notabiliza pela multiplicidade de temas que orientam as ações políticas e sociais dos coletivos, características próprias dos movimentos da multidão.

\section{NOTAS}

${ }^{1}$ Segundo Norris (2001), a internet foi recebida por um grupo de teóricos como a possibilidade concreta de ampliação da democracia; esse grupo era chamado de ciberotimista ou entusiastas da rede. Os chamados ciberpessimistas, por sua vez, apontam para restrições e deficit da internet na contribuição ao aprofundamento da sociedade democrática.

${ }^{2}$ Nessa e nas demais citações de textos publicados em outros idiomas, a tradução é livre.

${ }^{3}$ Segundo Recuero (2009), é o prestígio por meio do capital social relacional que um sujeito possui na rede.

${ }^{4}$ Seguem alguns autores de referência para os estudos de ciberpolítica e cibercultura: Chris Anderson, Manuel Castells, Pipa Norris, Mario Tascón, Yolanda Quintana, Howard Rheingold, Francisco Rüdiger, Henry Jenkins, Joan Subirat, Pierre Lévy, Sérgio Amadeu da Silveira, Dominique Wolton, André Lemos, Wilson Gomes, Raquel Ricuero entre outros. 


\section{REFERÊNCIAS}

BENKLER, Yochai.

Comunicação digital e a construção dos commons. São Paulo: Fundação Perseu Abramo. 2007.

BRASIL É O SEGUNDO...

Brasil é o segundo maior país no Facebook, diz pesquisa. Disponível em: http://g1.globo.com/ tecnologia/noticia/2012/05/brasil-e-o-segundomaior-pais-no-facebook-diz-pesquisa.html. Acesso em: 25 set. 2015. 2012.

CASTELLS, Manuel.

Redes de indignação e esperança: movimentos sociais na era da internet. Rio de Janeiro: Zahar. 2013.

CASTELLS, Manuel.

Comunicación y poder. Madrid: Alianza. 2009.

CASTELLS, Manuel.

Sociedade em rede. São Paulo: Paz e Terra. 1999.

DELEUZE, Gilles; GUATTARI, Félix.

Kafka: por uma literatura menor. Rio de Janeiro: Imago. 1977.

FACEBOOK ATINGE..

Facebook atinge 1 bilhão de usuários ativos mensais. Disponível em: http://g1.globo.com/ tecnologia/noticia/2012/10/facebook-atinge-1bilhao-de-usuarios-ativos-mensais.html. Acesso em: 25 set. 2015. 2012.

GOHN, Maria da Glória.

Manifestações de junho de 2013 no Brasil e praça dos indignados no mundo. Petrópolis: Vozes. 2014.

GOHN, Maria da Glória; BRINGEL, Breno M.

Movimentos sociais na era global. Petrópolis: Vozes. 2014.

HARDT, Michael; NEGRI, Antonio.

Multidão: guerra e democracia na era do Império. Rio de Janeiro: Record. 2005.

HOBBES, Thomas.

Leviatã ou matéria, forma e poder de um Estado eclesiástico e civil. São Paulo: Nova Cultural. 1988.

JENKINS, Henry.

Cultura da convergência. São Paulo: Aleph. 2008.
LEMOS, André; LÉVY, Pierre.

O futuro da internet: em direção a uma ciberdemocracia. São Paulo: Paulus. 2010.

LÉVY, Pierre.

A conexão planetária: o mercado, o ciberespaço, a consciência. São Paulo: Editora 34. 2001.

MARICATO, Ermínia.

É a questão urbana, estúpido! In: Maricato, Ermínia et al. Cidades rebeldes: Passe Livre e as manifestações que tomaram as ruas do Brasil. São Paulo: Boitempo; Carta Maior. p.19-26. 2013.

NEGRI, Antonio.

Cinco lições sobre Império. Rio de Janeiro: DP\&A. 2003.

NEGRI, Antonio.

Trabalho imaterial e subjetividade. In: Lazzarato, Maurizio; Negri, Antonio. Trabalho imaterial: formas de vida e produção de subjetividade. Rio de Janeiro: DP\&A. 2001.

NORRIS, Pippa.

Digital divide: civic engagement, information poverty, and the Internet worldwide. Cambridge: Cambridge University Press. 2001.

QUINTANA, Yolanda; TASCÓN, Mario.

Ciberativismo: las nuevas revoluciones de las multitudes conectadas. Madrid: Catarata. 2012.

RAMONET, Ignacio.

A explosão do jornalismo: das mídias de massa à massa de mídias. São Paulo: Publisher Brasil. 2012.

RECUERO, Raquel. Redes sociais na internet. Porto Alegre: Sulina. 2009.

RHEINGOLD, Howard.

Smart mobs: the next social revolution.

Cambridge: Perseus. 2002.

RUDIGER, Reignol.

O estatuto da cibercultura no Brasil. Logos, v.34, n.1. Disponível em: http://www.e-publicacoes. uerj.br/index.php/logos/article/view/1502/1595. Acesso em: 10 ago. 2015. 2011.

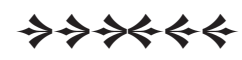

